\title{
Reproducibility and validity of an FFQ to assess usual intake of methyl-group donors
}

\author{
Sara Pauwels ${ }^{1,2, *}$, Ine Doperé ${ }^{1}$, Inge Huybrechts ${ }^{3}$, Lode Godderis ${ }^{1,4}$, Gudrun Koppen ${ }^{2}$ \\ and Greet Vansant ${ }^{1}$ \\ ${ }^{1} \mathrm{KU}$ Leuven, Department of Public Health and Primary Care, Centre Environment \& Health, Kapucijnenvoer 35 blok D \\ box 7001, 3000 Leuven, Belgium: ${ }^{2}$ Flemish Institute of Technological Research (VITO), Unit Environmental Risk and \\ Health, Mol, Belgium: ${ }^{3}$ International Agency for Research on Cancer, Dietary Exposure Assessment Group, Lyon, \\ France: ${ }^{4}$ IDEWE, External Service for Prevention and Protection at Work, Heverlee, Belgium
}

Submitted 21 August 2013: Final revision received 19 November 2014: Accepted 30 November 2014: First published online 14 January 2015

\begin{abstract}
Objective: To develop and validate a novel FFQ to assess the daily intake of four methyl-group donors (methionine, choline, betaine and folate).

Design: The relative validity of the FFQ was assessed by comparison with $7 \mathrm{~d}$ estimated diet records ( $n$ 80) and its reproducibility was evaluated by repeated administrations 6 weeks apart ( $n$ 92). Paired Student $t$ tests were used to compare group means and de-attenuated intra-class correlations to investigate the ability of the FFQ to rank individuals according to their methyl-group donor intake. De-attenuated intra-class correlation coefficients were calculated between the test and reference method for methionine, choline, betaine, folate and the sum of methyl-group donors. The weighted kappa $\left(\kappa_{\mathrm{w}}\right)$ was calculated as a measure of tertile agreement.

Setting: Flanders, Belgium.

Subjects: The FFQ was validated among Flemish women of reproductive age (18-35 years).

Results: The questionnaire had an acceptable ranking ability $(r=0 \cdot 32-0 \cdot 68$; $\left.\kappa_{\mathrm{w}}=0 \cdot 10-0 \cdot 35\right)$, but overestimated the daily intake of folate $(280 \cdot 6 \mu \mathrm{g} v .212 .0 \mu \mathrm{g})$ and betaine (179.1 mg $v .147 .0 \mathrm{mg}$ ) compared with the $7 \mathrm{~d}$ estimated diet record. Cross-classification analysis indicated that $20 \%$ (choline) of the participants were grossly misclassified in the validation study. The correlation between repeated administrations was good $(r=0 \cdot 62-0 \cdot 83)$ with a maximal misclassification of $7 \%$ for betaine $\left(\kappa_{\mathrm{w}}=0 \cdot 44-0 \cdot 66\right)$.

Conclusions: These results indicate that this newly developed FFQ is a reliable instrument with acceptable validity for ranking individuals according to methylgroup donor intake (except for a poor agreement for choline $\left(\kappa_{\mathrm{w}}=0 \cdot 10\right)$ and a fair ranking ability for betaine $(r=0 \cdot 32))$ in Flemish women of reproductive age.
\end{abstract}

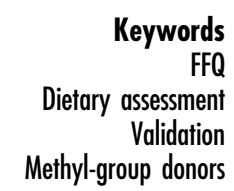

The impact of nutrition on the methylome has received much attention over the past years ${ }^{(1)}$. The methylome describes the distribution of methylated sequences within a given genome without changes to the DNA sequence itself. In man, DNA methylation takes place at the C-5 position of cytosine in $\mathrm{CpG}$ dinucleotides ${ }^{(1)}$. One-carbon metabolism is central to the methylation of DNA (Fig. 1). The main nutrients implicated are methyl-group donors and cofactors including methionine, choline, betaine, folate, vitamin $\mathrm{B}_{6}$ and vitamin $\mathrm{B}_{12}$, which are all derived from the diet. Consequently, any dietary factor influencing this pathway may affect DNA methylation ${ }^{(2,3)}$. The transfer of a methyl group to DNA depends on the availability of $S$-adenosylmethionine. $S$-Adenosylmethionine is derived from methionine, which is de-methylated through the action of DNA methyltransferases to $S$-adenosylhomocysteine ${ }^{(4)}$. $S$-Adenosylhomocysteine is hydrolysed to homocysteine in a reversible reaction that strongly favours $S$-adenosylhomocysteine synthesis compared with hydrolysis. Homocysteine can leave the methionine cycle through the transsulfuration pathway or can be re-methylated back to methionine with vitamin $\mathrm{B}_{12}$ acting as a cofactor and 5-methyltetrahydrofolate acting as substrate ${ }^{(5)}$.

In the context of a prospective observational study investigating the relationship between the intake of maternal methyl-group donors during each trimester of pregnancy and offspring DNA methylation, an instrument assessing the daily intake of methyl-group donors was 


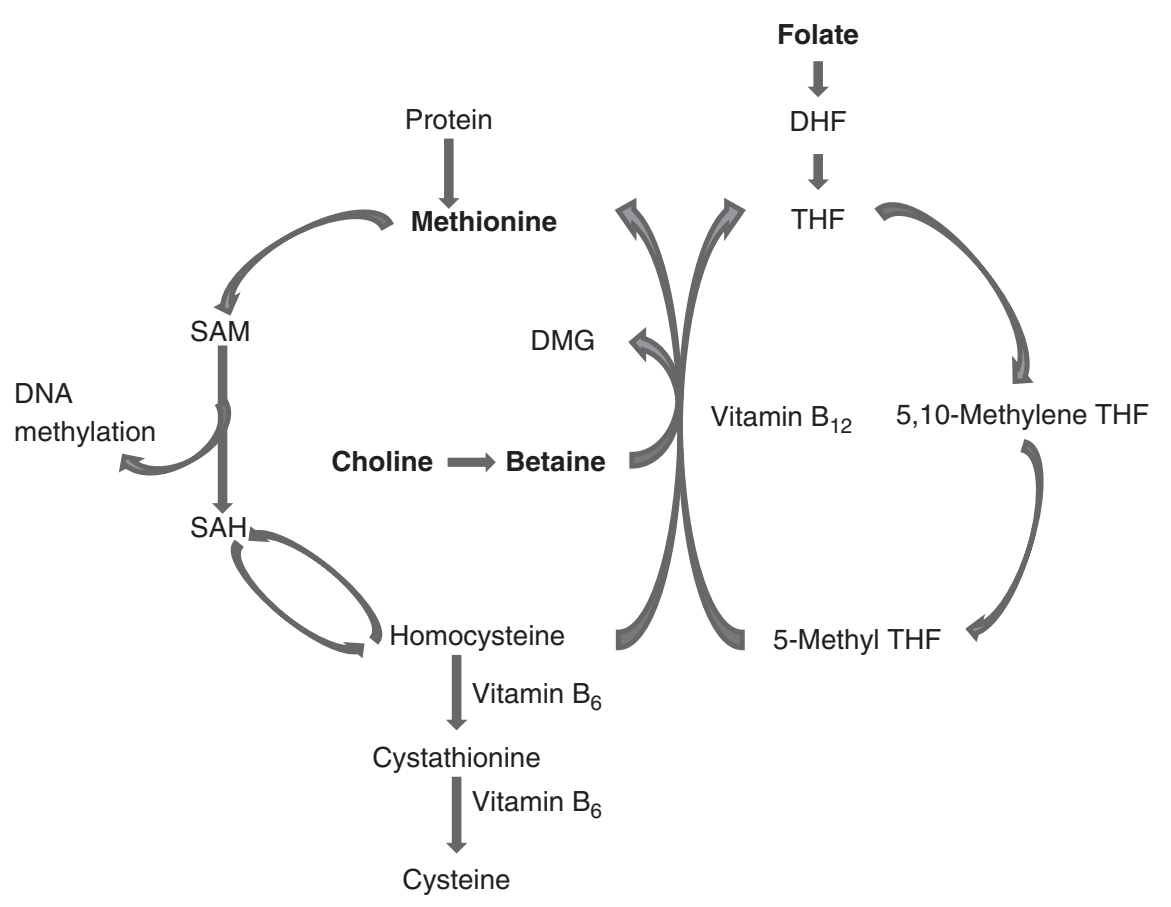

Fig. 1 Simplified scheme of one-carbon metabolism. Nutrients included in the present study appear in bold. 5-Methyl THF, 5-methyl tetrahydrofolate; 5,10-methylene THF, 5,10-methylene tetrahydrofolate; DHF, dihydrofolate; DMG, dimethylglycine; SAM, S-adenosylmethionine; SAH, S-adenosylhomocysteine; THF, tetrahydrofolate

needed. At study onset, no such tool was available since food composition databases for betaine and choline only recently became available ${ }^{(6)}$. It is preferred to use FFQ over diet records or $24 \mathrm{~h}$ recalls, because they have shown to be more suitable and accurate in assessing long-term or habitual exposure to specific nutrients involved in onecarbon metabolism (e.g. folate) ${ }^{(7)}$.

Studies on the effect of maternal diet and the methylome of the offspring are showing the importance of maternal nutrition. Heijmans et al. ${ }^{(8)}$ explained the long-term effects of prenatal famine on the offspring methylome. They found an average decrease of $5.2 \%$ in DNA methylation on the insulin-like growth factor 2 (IGF2) gene locus, showing that maternal undernutrition (low intake of methyl-group donors) can indeed have persistent effects on the offspring throughout adulthood. A similar study by Tobi et al. ${ }^{(9)}$ suggested that famine exposure (in utero) only held a long-term effect on the offspring IGF2 gene when the exposure was periconceptional. On the other hand, Steegers-Theunissen et $a l .{ }^{(10)}$ found that periconceptional supplementation of mothers with $400 \mu \mathrm{g}$ of folic acid (methyl-group donor) daily was associated with epigenetic changes ( $4.5 \%$ higher DNA methylation) in the same IGF2 locus in the child.

A novel, self-administered, semi-quantitative FFQ was designed to estimate the daily intake of methionine, choline, betaine, folate and the sum of methyl-group donors in women of reproductive age (18-35 years). The aim of the present study was to assess the validity and reproducibility of the FFQ using the $7 \mathrm{~d}$ estimated diet record (7 d EDR) as reference method. The reproducibility of the FFQ was determined by administering the FFQ at two time points ( 6 weeks apart) to the same group of women, so that the association between the two responses could be assessed. Also the validity of the FFQ was determined to assess the degree to which the FFQ agreed with the reference method ( $7 \mathrm{~d}$ EDR). Even a subtle change in the design of the FFQ or the use of the FFQ in different demographic groups and cultures might affect its performance, so each new FFQ should be validated ${ }^{(11)}$.

\section{Materials and methods}

\section{Study design}

A total of 296 women of reproductive age (18-35 years) were invited to participate in the study. Female students or employees of the Catholic University of Leuven were asked to take part in the study. An invitation letter, sent through mail or personally delivered, informed the participants about the aim of the study. They were asked to return their first completed FFQ (FFQ1) and their written consent in a sealed envelope. Six weeks later the second FFQ (FFQ2) together with the $7 \mathrm{~d}$ EDR was distributed to only those participants from whom we received FFQ1. Participants were instructed to fill in the FFQ at day one, to start the $7 \mathrm{~d}$ EDR at day two, and to put the dates of completion on the documents. Detailed instructions for filling in the FFQ and EDR were given. The field work of the validation and reproducibility study was carried out from February to March 2012. 
Of the 296 women invited to participate in the study, 161 women (54\%) returned FFQ1. The 161 women were again invited to take part in the second phase of the study and of them ninety-eight (61\%) completed FFQ2 and the $7 \mathrm{~d}$ EDR. Only FFQ without missing values were included in the reproducibility study, so after exclusion of incomplete FFQ and outliers ninety-two women were included in the analysis. Similarly, only complete $7 \mathrm{~d}$ EDR including seven completed record days and containing sufficiently detailed descriptions of the food products (including brand names, the food type (e.g. the use of whole, semiskimmed or skimmed milk, the type of bread used, etc.)) and portion sizes (expressed as household measures, standard units (e.g. a medium-sized apple) or units like grams or litres) consumed could be used in the validation study; so after exclusion of incomplete $7 \mathrm{~d}$ EDR eighty women were included in the analysis.

The study was conducted according to the guidelines laid down in the Declaration of Helsinki and all procedures involving human subjects were approved by the UZ Leuven-Committee for Medical Ethics (reference number: ML7975). Written informed consent was obtained from all participants.

\section{FFQ}

The Flemish, self-administered, semi-quantitative FFQ contained questions on the average consumption of fifty-one food items during the past 3 months (see online supplementary material, Part 1). The time frame of 3 months was chosen because this FFQ will be used to assess the intake of maternal methyl-group donors during each trimester of pregnancy. The concept and structure of the FFQ were based on a previously developed and validated FFQ estimating usual daily fat, fibre, alcohol, caffeine and theobromine intakes among Belgian postmenopausal women ${ }^{(12)}$. However, the food list included in our newly developed FFQ (fifty-one food items) was adopted considering our study aims, namely to estimate the daily intake of methionine, choline, betaine, folate and the sum of methyl-group donors. Food items included in an FFQ should be eaten reasonably often by the population and/or contain a substantial amount of one or more nutrients of interest ${ }^{(11)}$.

The fifty-one food items included in our FFQ were food items that are part of the Belgian diet (National Food Consumption Survey) and/or had a high nutrient content (>90th percentile) of one the four methyl-group donors. All food items were listed according to their nutrient content (from high to low) and the top $10 \%$ food items were selected. Participants were asked to indicate their answer from a list of frequencies: 'never or less than once per month'; '1-3 days per month'; '1 day per week'; '2-4 days per week'; '5-6 days per week'; or 'every day'(13). The FFQ also contained three to five daily portion size categories per food item and a list of common standard measures as examples. For some food groups, additional questions were asked regarding the type, such as specific type of fruit juice. All returned FFQ were reviewed for completeness and written comments. Frequency data from the FFQ were converted to servings per day (e.g. 1 serving/ week $=0.14$ serving $/ d$ ) to standardize the different frequency categories by means of a common unit (servings/d). Portion size categories were converted to a portion (grams) per serving by considering the mean of the portion size range that was chosen by the participant. The usual food intakes were computed by multiplying the servings per day with the portion size per serving. Usual nutrient (methionine, choline, betaine and folate) intakes were calculated by multiplying the usual food intakes with the nutritional value per $100 \mathrm{~g}$ of product. The food composition data were based on the Dutch NEVO food composition database $^{(14)}$ for folate, the German BLS nutrient database ${ }^{(15)}$ for methionine and the US Department of Agriculture (USDA) database for the Choline Content of Common Foods ${ }^{(6)}$ for choline and betaine. The USDA database was also used for the nutrient content of folate and methionine if not found in the NEVO and BLS database, respectively. Databases of neighbouring countries or the USDA database for choline and betaine content were used since the Belgian food composition database NUBEL ${ }^{(16)}$ does not contain the four nutrients of interest.

\section{Estimated diet record (reference method)}

In the present relative validation study the $7 \mathrm{~d}$ EDR was chosen as the reference method. The participants were given guidelines for filling in their diary and we also provided one correctly filled in day as an example. The participants were asked to report all consumed foods and drinks over seven consecutive days. In the $7 \mathrm{~d}$ EDR, days are subdivided into six eating occasions (breakfast, morning snacks, lunch, afternoon snacks, dinner and evening snacks). Detailed information on the type (including brand names, the food type (e.g. use of whole, semi-skimmed or skimmed milk, the type of bread used, etc.)) and portion size (expressed as household measures, standard units (e.g. a medium-sized apple) or units like grams or litres) of the foods consumed was collected using an open entry format. Only complete food diaries, including seven completed record days and containing sufficiently detailed descriptions of the food products and portion sizes consumed, were taken into consideration. In total seventeen EDR had to be excluded because of incomplete data. The complete $7 \mathrm{~d}$ EDR were coded and entered into a diet entry and storage program (NUBEL Voedingsplanner ${ }^{(17)}$ ) using a manual on food portions and household measures ${ }^{(18)}$. Methionine, choline, betaine and folate are not included in the Belgian food composition table NUBEL ${ }^{(16)}$, so the diet records were linked to the same food composition databases as for the FFQ (Dutch NEVO food composition database ${ }^{(14)}$, the USDA database for the Choline Content of Common Foods ${ }^{(6)}$ and the German BLS nutrient database $\left.{ }^{(15)}\right)$. Some typically Belgian 
food products like 'speculaas', a type of shortcrust biscuit, are not included in the USDA database. For these products, the choline and betaine content of the American variety was entered in the database. For example, a ginger biscuit was used for the choline and betaine content of 'speculaas'.

\section{Statistical analysis}

Statistical analyses were carried out using the statistical software package IBM SPSS for Windows version 20.0. Results were considered statistically significant at a twotailed $\alpha$ level of $0 \cdot 05$. Tests for normality of the data were performed using the Kolmogorov-Smirnov test. Data were normally distributed for the validation study and reproducibility study (after exclusion of three outliers with unusual eating behaviours); consequently only parametric tests were used during analysis. Means and standard deviations of the four methyl-group donating nutrients and the sum of all were estimated from the FFQ and $7 \mathrm{~d}$ EDR. Paired Student's $t$ test was used to determine significant mean differences. Associations were described using intraclass correlations. Correlations ranging from 0.00 to 0.25 indicate weak or no relationship; those from 0.25 to 0.50 suggest a fair degree of relationship; values of 0.50 to 0.75 are moderate to good; and values above 0.75 are considered good to excellent ${ }^{(19)}$. In the validity study, the de-attenuated intra-class correlation coefficients were calculated to correct for within-person variation in the $7 \mathrm{~d}$ EDR. This de-attenuated correlation is calculated as the ratio of the inter-individual (true between-subject variation in usual intake) CV to the intra-individual (day-by-day variation in intake, day-of-the-week variation in females) $\mathrm{CV}^{(20)}$. Agreement between the $7 \mathrm{~d}$ EDR and the FFQ at an individual level was assessed using mean difference, standard deviation and limits of agreement of the difference, and visually represented in a Bland-Altman plot ${ }^{(21)}$. Individual results for nutrient intake estimated by the $7 \mathrm{~d}$
EDR and FFQ were classified into tertiles to assess the questionnaire's ability to rank individuals according to the intake as in the $7 \mathrm{~d} \mathrm{EDR}^{(13)}$. The percentage classified into the same and opposite tertile was calculated. Agreement between both methods was assessed using weighted kappa $\left(\kappa_{\mathrm{w}}\right)$ statistics, calculated with a linear set of weights ${ }^{(22)}$. The measurement error of the FFQ was analysed using 'actual values for surrogate categories, ${ }^{\text {(13) }}$. One-way ANOVA test was used to determine significant differences in means between tertiles. Specificity was defined as the proportion of those with a daily intake above the guidelines ${ }^{(23-25)}$ on the basis of the $7 \mathrm{~d}$ EDR who also fell above the guidelines on the FFQ (true negatives). Sensitivity was the proportion of those with a daily intake below the guidelines on the basis of the $7 \mathrm{~d}$ EDR who also fell below the guidelines on the FFQ (true positives). The positive predictive value was the proportion of those identified by the FFQ as having an inadequate intake who actually had an inadequate intake (according to the $7 \mathrm{~d}$ EDR). The negative predictive value was the proportion of those identified by the FFQ as having an adequate intake who actually had an adequate intake (according to the $7 \mathrm{~d}$ EDR; see online supplementary material, Part 2).

\section{Results}

\section{Validation study}

In total, eighty women were included in the validation study. Table 1 presents the characteristics of the study participants. Women included in the validation study had a mean age of 23 (sD 4.1) years (range 18-35 years), a mean weight of 60 (sD 9.6) $\mathrm{kg}$, a mean height of 1.68 (SD 0.05$) \mathrm{m}$ and a mean BMI of 21.7 (SD 3.2 ) $\mathrm{kg} / \mathrm{m}^{2}$. Twenty-six women $(32.5 \%)$ were employed at the time of the study, so fifty-four participants $(67 \cdot 5 \%)$ were students. Only two women $(2.5 \%)$ smoked at the time of the study.

Table 1 Characteristics of the study participants: Flemish women of reproductive age, female students or employees of the Catholic University of Leuven, February-March 2012

\begin{tabular}{|c|c|c|c|}
\hline Variable/category & Validation study ( $n$ 80) & Reproducibility study ( $n$ 92) & All women with dietary data $(n 161)$ \\
\hline \multicolumn{4}{|l|}{ Age (years) } \\
\hline Mean & 23 & 23 & 23 \\
\hline $\mathrm{SD}$ & 4.1 & 3.9 & 4.2 \\
\hline Range & $18-35$ & $18-35$ & $19-36$ \\
\hline \multicolumn{4}{|l|}{ Weight (kg) } \\
\hline Mean & $60 \cdot 0$ & 60.2 & 61.7 \\
\hline SD & 9.6 & $9 \cdot 8$ & $9 \cdot 4$ \\
\hline \multicolumn{4}{|l|}{ Height $(m)$} \\
\hline Mean & 1.68 & 1.68 & 1.68 \\
\hline SD & 0.05 & 0.06 & 0.06 \\
\hline \multicolumn{4}{|l|}{ BMI $\left(\mathrm{kg} / \mathrm{m}^{2}\right)$} \\
\hline Mean & $21 \cdot 7$ & $21 \cdot 7$ & $21 \cdot 7$ \\
\hline $\mathrm{SD}$ & 3.2 & 3.1 & 3.0 \\
\hline \multicolumn{4}{|l|}{ Employment } \\
\hline$\%$ & 32.5 & 33.7 & 32.5 \\
\hline \multicolumn{4}{|l|}{ Current smokers } \\
\hline$\%$ & $2 \cdot 6$ & $2 \cdot 1$ & 3.7 \\
\hline
\end{tabular}


Table 2 Mean intakes of methionine, choline, betaine, folate and SUM estimated with the $7 \mathrm{~d}$ EDR and FFQ1 among Flemish women ( $n$ 80) of reproductive age (18-35 years), February-March 2012

\begin{tabular}{|c|c|c|c|c|c|c|c|c|c|c|}
\hline & \multicolumn{2}{|c|}{$7 d$ EDR } & \multicolumn{2}{|c|}{ FFQ1 } & \multirow[b]{2}{*}{$P^{*}$} & \multicolumn{2}{|c|}{ FFQ1 - 7 d EDR } & \multicolumn{3}{|c|}{ Correlation coefficient } \\
\hline & Mean & SD & Mean & SD & & Mean difference & SD & ICC & $\mathrm{ICC} \dagger$ & $P$ \\
\hline Methionine $(\mathrm{mg} / \mathrm{d})$ & 1732.4 & 388.9 & $1699 \cdot 1$ & 694.3 & 0.621 & -33.3 & 600.6 & 0.43 & 0.62 & $<0.001$ \\
\hline Choline (mg/d) & 284.3 & $61 \cdot 6$ & 286.6 & $105 \cdot 1$ & 0.840 & $2 \cdot 3$ & $104 \cdot 2$ & 0.27 & 0.42 & 0.008 \\
\hline Betaine $(\mathrm{mg} / \mathrm{d})$ & 147.0 & 51.0 & $179 \cdot 1$ & 73.0 & $<0.001$ & $32 \cdot 1$ & 78.0 & 0.23 & 0.32 & 0.018 \\
\hline Folate $(\mu \mathrm{g} / \mathrm{d})$ & $212 \cdot 0$ & $76 \cdot 7$ & $280 \cdot 6$ & $122 \cdot 6$ & $<0.001$ & $68 \cdot 6$ & 88.0 & 0.58 & 0.68 & $<0.001$ \\
\hline SUM $(\mathrm{mg} / \mathrm{d})$ & 2163.9 & $455 \cdot 3$ & 2165.1 & 833.2 & 0.988 & 1.27 & 733.0 & 0.40 & 0.57 & $<0.001$ \\
\hline
\end{tabular}

SUM, sum of methyl-group donors; $7 \mathrm{~d}$ EDR, $7 \mathrm{~d}$ estimated diet record; FFQ1, first administration of the FFQ; ICC, intra-class correlation coefficient. *Paired Student's $t$ test was used to determine significant differences between means. †De-attenuated ICC.

Mean intakes of methionine, choline, betaine, folate and the sum of methyl-group donors (SUM) estimated with the $7 \mathrm{~d}$ EDR and the FFQ, mean differences, and raw and de-attenuated intra-class correlation coefficients are presented in Table 2. The FFQ overestimated the intake of folate and betaine in comparison with the $7 \mathrm{~d}$ EDR. The mean intakes of folate and betaine were significantly different, but fair to good de-attenuated correlation coefficients ranged from 0.32 (betaine) to 0.68 (folate). The mean difference in methionine intake between FFQ1 and the $7 \mathrm{~d}$ EDR was -33.3 (sD 600.6) $\mathrm{mg} / \mathrm{d}$, demonstrating that the FFQ underestimated methionine intake. The mean differences in choline, betaine, folate and SUM intakes between the two methods were $2 \cdot 3$ (sD 104.2) mg/d, 32.1 (sD 78.0) mg/d, 68.6 (sD 88.0$) \mu \mathrm{g} / \mathrm{d}$ and 1.27 (sD 733.0) $\mathrm{mg} / \mathrm{d}$, respectively, demonstrating that the FFQ overestimated choline, betaine, folate and SUM intakes compared with the $7 \mathrm{~d}$ EDR. This is shown graphically in Bland-Altman plots (Fig. 2), which reveal that outliers widened the limits of agreement and made the plots more divergent. This divergent pattern could indicate increasing bias with increasing intakes. Cross-classification analysis indicated that about half of the participants (40-54\%) were classified correctly, while 9\% (methionine) to $20 \%$ (choline) of them were grossly misclassified (Table 3). Results from the $\kappa_{\mathrm{w}}$ statistics showed fair agreement between the FFQ and $7 \mathrm{~d}$ EDR $(0.21$ for betaine to 0.35 for methionine and SUM), but a poor agreement for choline (0.10). Actual values for surrogate FFQ tertiles showed a progressive increase in $7 \mathrm{~d}$ EDR intakes of methionine, betaine, folate and SUM between the first and third FFQ tertile (Table 4) with statistically significant differences in mean intake between the tertiles for all nutrients except for choline. The specificity and sensitivity of the FFQ, for indicating women with lower nutrient intake than the recommended daily intake, were $87 \%$ and $37 \%$ for folate, $33 \%$ and $97 \%$ for choline, and $100 \%$ and $100 \%$ for methionine, respectively. The positive and negative predictive values were $76 \%$ and $55 \%$ for folate, $97 \%$ and $33 \%$ for choline, and $100 \%$ and $100 \%$ for methionine, respectively. The specificity and sensitivity of the FFQ for betaine could not be calculated since there is no recommended daily intake for betaine.

\section{Reproducibility study}

In the reproducibility study, ninety-two women were included. Table 1 presents the characteristics of the study participants. Women included in the reproducibility study had a mean age of 23 (sD 3.9) years (range 18-35 years), a mean weight of 60.2 (SD 9.8) kg, a mean height of 1.68 (sD 0.06$) \mathrm{m}$ and a mean BMI of 21.7 (sD $3 \cdot 1) \mathrm{kg} / \mathrm{m}^{2}$. Twenty-seven women (33.7\%) were employed at the time of the study, so sixty-five participants $(66.3 \%)$ were students. Only two women (2.1\%) smoked at the time of the study. Mean intakes of methionine, choline, betaine, folate and SUM from FFQ1 and FFQ2 were significantly different and correlation coefficients ranged from 0.62 (betaine) to 0.83 (folate; Table 5). Cross-classification analysis indicated that $1 \%$ (methionine) to $7 \%$ (betaine) of the participants were grossly misclassified, while more than half of them (57-71\%) were classified correctly (Table 6). Results from the $\kappa_{\mathrm{w}}$ statistics showed moderate to good agreement ( 0.44 for betaine to 0.66 for methionine).

\section{Discussion}

\section{Validation study}

The FFQ has an acceptable ranking ability $(r=0.32-0.68$; $\left.\kappa_{\mathrm{w}}=0 \cdot 10-0 \cdot 35\right)$, but in general overestimates the daily intake of folate $(280.6 \mu \mathrm{g} v .212 .0 \mu \mathrm{g})$ and betaine $(179.1 \mathrm{mg} v$. $147.0 \mathrm{mg}$ ) compared with the $7 \mathrm{~d}$ EDR. Cross-classification analysis indicated that $20 \%$ (choline) of the women were grossly misclassified in the validation study.

Based on the comparison of means, the FFQ seems to overestimate the mean intakes of folate (which has also been reported in previous studies ${ }^{(26-28)}$ ) and betaine compared with the $7 \mathrm{~d}$ EDR. Unfortunately, we could not determine whether this was due to over-reporting, because our FFQ was not designed to estimate energy intake. A possible explanation is the contribution of vegetables to total folate intake. In our FFQ, vegetables contributed $34 \%$ of total folate intake, which is comparable to the $36 \%$ found in another $\mathrm{FFQ}^{(28)}$. Fruit and vegetables are most often over-reported in $\mathrm{FFQ}^{(29)}$, possibly because these are socially desirable foods ${ }^{(30)}$. Another explanation 
(a)

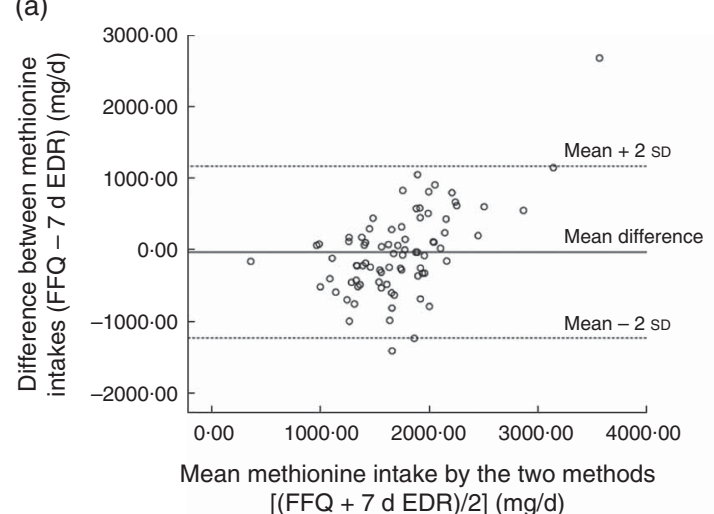

(c)

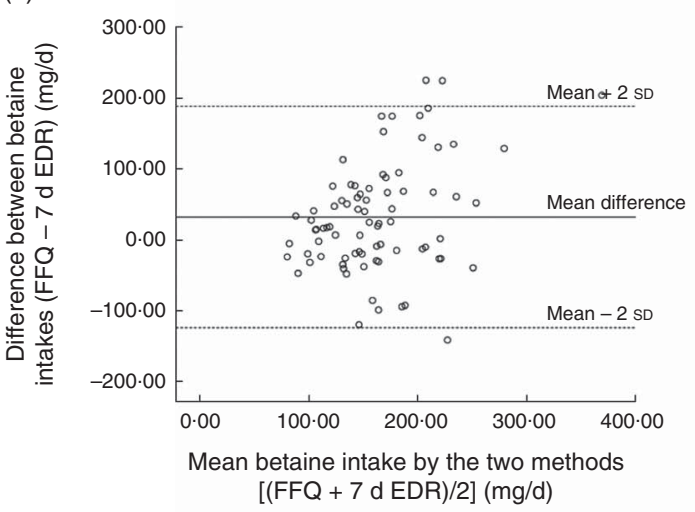

(e)

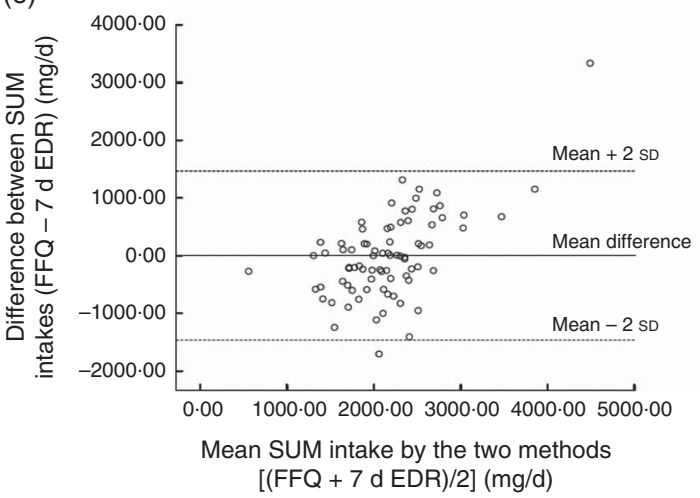

(b)

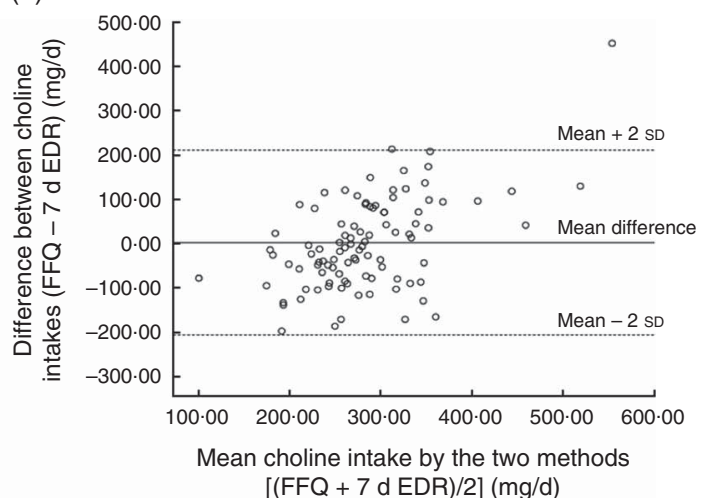

(d)

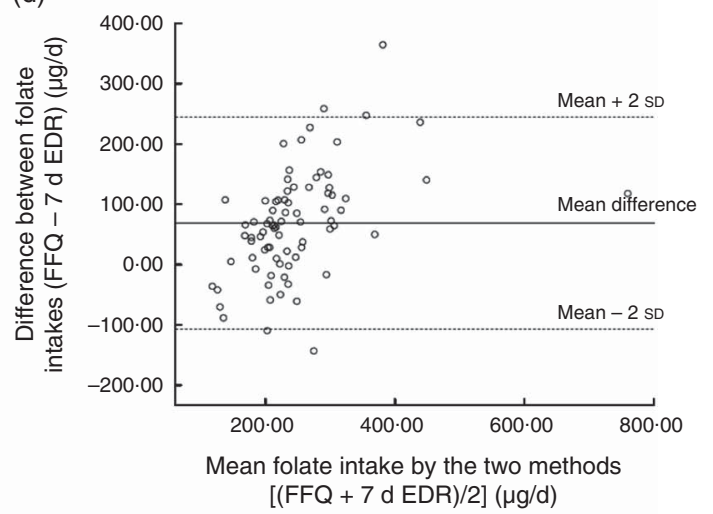


Table 3 Cross-classification analysis and $\kappa_{\mathrm{w}}$ statistics for the $7 \mathrm{~d}$ EDR and FFQ tertiles of usual daily intakes of methylgroup donors among Flemish women ( $n$ 80) of reproductive age (18-35 years), February-March 2012

\begin{tabular}{lcccr}
\hline & \multicolumn{2}{c}{ Percentage classified in } & & \\
\cline { 2 - 4 } & Same tertile & Opposite tertile & $\kappa_{\mathrm{w}}$ & $95 \% \mathrm{Cl}$ \\
\hline Methionine & 51 & 9 & 0.35 & $0.20,0.51$ \\
Choline & 40 & 20 & 0.10 & $0.06,0.25$ \\
Betaine & 44 & 14 & 0.21 & $0.05,0.36$ \\
Folate & 51 & 16 & 0.27 & $0.11,0.42$ \\
SUM & 54 & 11 & & 0.35 \\
Classification by chance & 33 & 22 & & \\
\hline
\end{tabular}

$\kappa_{\mathrm{w}}$, weighted kappa; $7 \mathrm{~d}$ EDR, $7 \mathrm{~d}$ estimated diet record; SUM, sum of methyl-group donors.

Table 4 Use of actual values for surrogate tertiles to compare the usual daily intakes of methyl-group donors from the FFQ with those from the $7 \mathrm{~d}$ EDR among Flemish women $(n 80)$ of reproductive age (18-35 years), February-March 2012

\begin{tabular}{|c|c|c|c|c|c|c|c|}
\hline & \multicolumn{2}{|c|}{ 1st tertile } & \multicolumn{2}{|c|}{ 2nd tertile } & \multicolumn{2}{|c|}{ 3rd tertile } & \multirow[b]{2}{*}{$P^{\star}$} \\
\hline & Mean & SD & Mean & SD & Mean & SD & \\
\hline Methionine $(\mathrm{mg} / \mathrm{d})$ & $1540 \cdot 7$ & 437.0 & $1742 \cdot 6$ & $322 \cdot 2$ & $1906 \cdot 8$ & 321.9 & 0.002 \\
\hline Choline $(\mathrm{mg} / \mathrm{d})$ & 269.5 & $56 \cdot 9$ & $292 \cdot 0$ & $66 \cdot 0$ & $290 \cdot 8$ & $61 \cdot 2$ & 0.334 \\
\hline Betaine (mg/d) & $128 \cdot 4$ & 38.9 & $146 \cdot 8$ & $50 \cdot 3$ & $165 \cdot 1$ & $56 \cdot 9$ & 0.030 \\
\hline Folate $(\mu \mathrm{g} / \mathrm{d})$ & $192 \cdot 2$ & $56 \cdot 1$ & $197 \cdot 3$ & 34.2 & $245 \cdot 8$ & $109 \cdot 0$ & 0.017 \\
\hline SUM (mg/d) & $1925 \cdot 0$ & $515 \cdot 6$ & 2213.8 & $342 \cdot 6$ & 2343.9 & 404.5 & 0.002 \\
\hline
\end{tabular}

$7 \mathrm{~d}$ EDR, $7 \mathrm{~d}$ estimated diet record; SUM, sum of methyl-group donors.

${ }^{*}$ One-way ANOVA was used to determine significant differences in means between tertiles.

Table 5 Mean intakes of methionine, choline, betaine, folate and SUM estimated with FFQ1 and FFQ2 among Flemish women ( $n$ 92) of reproductive age (18-35 years), February-March 2012

\begin{tabular}{|c|c|c|c|c|c|c|c|c|c|}
\hline & \multicolumn{2}{|c|}{ FFQ1 } & \multicolumn{2}{|c|}{ FFQ2 } & \multirow[b]{2}{*}{$P^{*}$} & \multicolumn{2}{|c|}{ FFQ1 - FFQ2 } & \multicolumn{2}{|c|}{ Correlation coefficient } \\
\hline & Mean & SD & Mean & SD & & Mean difference & SD & $\mathrm{ICC}$ & $P$ \\
\hline Methionine $(\mathrm{mg} / \mathrm{d})$ & $1607 \cdot 7$ & $565 \cdot 6$ & $1489 \cdot 3$ & $472 \cdot 3$ & $<0.001$ & 118.4 & $345 \cdot 0$ & 0.78 & $<0.001$ \\
\hline Folate $(\mu \mathrm{g} / \mathrm{d})$ & 265.6 & $105 \cdot 6$ & $243 \cdot 7$ & $90 \cdot 1$ & $<0.001$ & $22 \cdot 0$ & $57 \cdot 1$ & 0.83 & $<0.001$ \\
\hline Betaine $(\mathrm{mg} / \mathrm{d})$ & 174.8 & $67 \cdot 4$ & $155 \cdot 5$ & $52 \cdot 6$ & $<0.001$ & 19.2 & 52.9 & 0.62 & $<0.001$ \\
\hline Choline (mg/d) & $272 \cdot 8$ & 88.5 & $255 \cdot 3$ & $76 \cdot 2$ & $<0.001$ & $17 \cdot 4$ & $52 \cdot 8$ & 0.80 & $<0.001$ \\
\hline SUM (mg/d) & 2055.6 & 677.2 & $1900 \cdot 4$ & $566 \cdot 6$ & $<0.001$ & $155 \cdot 1$ & $415 \cdot 6$ & 0.78 & $<0.001$ \\
\hline
\end{tabular}

SUM, sum of methyl-group donors; FFQ1, first administration of the FFQ; FFQ2, second administration of the FFQ; ICC, intra-class correlation coefficient.

*Paired Student's $t$ test was used to determine significant differences between means.

Table 6 Cross-classification analysis and $k_{w}$ statistics for the FFQ1 and FFQ2 tertiles of usual daily intakes of methylgroup donors among Flemish women ( $n$ 92) of reproductive age (18-35 years), February-March 2012

\begin{tabular}{lcccr}
\hline & \multicolumn{2}{c}{ Percentage classified in } & & \\
\cline { 2 - 4 } & Same tertile & Opposite tertile & $\kappa_{\mathrm{w}}$ & $95 \% \mathrm{Cl}$ \\
\hline Methionine & 71 & 1 & 0.66 & $0.51,0.80$ \\
Choline & 60 & 3 & 0.51 & $0.36,0.65$ \\
Betaine & 57 & 7 & 0.44 & $0.29,0.58$ \\
Folate & 70 & 2 & 0.63 & $0.49,0.78$ \\
SUM & 71 & 3 & 0.63 & $0.49,0.78$ \\
Classification by chance & 33 & 22 & &
\end{tabular}

$\kappa_{\mathrm{w}}$, weighted kappa; FFQ1, first administration of the FFQ; FFQ2, second administration of the FFQ; SUM, sum of methyl-group donors.

correlation coefficients observed in the present study are between 0.40 and 0.68 , we can conclude that the FFQ has a good ranking ability (except for betaine $(0.32)$ ). In the present study we found a de-attenuated correlation of 0.68 for folate. Longnecker et al. ${ }^{(26)}$ compared nutrient intakes assessed with diet records and an FFQ with 116 food items in 138 men and women. For folate, they found a de-attenuated Pearson correlation coefficient of 0.42 , which 
is lower than the de-attenuated correlation coefficient found in the present study (0.68). Pufelete et al. ${ }^{(28)}$ developed a short FFQ to assess folate intake and validated it against a $7 \mathrm{~d}$ weighed diet record. For women, the correlation coefficient between the two methods was 0.30 . A higher de-attenuated Pearson correlation coefficient for folate $(0.77)$ was found by Sevak et $a l .{ }^{(27)}$. They validated an FFQ with 207 food items against $24 \mathrm{~h}$ recalls in 100 women. No correlation coefficients for betaine and choline were found in the literature, since a food composition database only became available a few years ago ${ }^{(6,32)}$. Also, no validation papers that assess the intake of methionine using an FFQ were found in the literature.

The present cross-classification analysis showed that the FFQ classified $40 \%$ of the women for choline and $54 \%$ for the sum of methyl-group donors in the same tertile, and that there was a maximal misclassification of $20 \%$ for choline. The $\kappa_{\mathrm{w}}$ values showed a fair agreement between the FFQ and $7 \mathrm{~d}$ EDR, but a poor agreement for choline. Sevak et al. ${ }^{(27)}$ reported a moderate agreement $\left(\kappa_{\mathrm{W}}=0.44\right)$ for folate between their FFQ and multiple $24 \mathrm{~h}$ recalls. They found that the FFQ classified $41 \%$ of the women in the same quartile for folate, as opposed to the $51 \%$ found in the present study. A lower misclassification of $5 \%$ (16\% in the present study) and a similar classification of $45 \%$ ( $41 \%$ in the present study) in the same tertile for folate (in women) was found by Pufulete et al. ${ }^{(28)}$, who developed a short FFQ to assess folate intake (in men and women) and validated it against a $7 \mathrm{~d}$ weighed diet record.

Since the actual values for surrogate tertiles showed the expected significant stepwise increase in nutrient intake, we concluded that the FFQ could reliably distinguish extreme nutrient intakes (except for choline).

The Bland-Altman plots showed large limits of agreement (mean difference $\pm 2 \mathrm{sD}$ ) between the two methods, indicating the limited use of the FFQ to estimate nutrient intake for individuals. The observed divergence in these plots suggests a greater difficulty in estimating nutrient intake with higher mean nutrient intakes. However, the FFQ was developed to classify and rank participants according to their intake in an epidemiological setting, not to assess intake at an individual level.

Also, the FFQ is not a good tool to use at an individual level for estimating the intake of folate with the Belgian Health Council guidelines ${ }^{(23)}$ as reference values, because $33 \%$ of the women would lose the possibility of receiving a required intervention (daily folate intake $<200 \mu \mathrm{g}$ ). The specificity and sensitivity of the other nutrients were more acceptable.

\section{Reproducibility study}

The correlation between repeated administrations was $\operatorname{good}(r=0.62-0.83)$ with a maximal misclassification of $7 \%$ for betaine $\left(\kappa_{\mathrm{w}}=0 \cdot 44-0 \cdot 66\right)$.

Lower mean intakes of all of the nutrients (7-12\% lower) were observed in the second questionnaire administration. Villamor et $a l .^{(33)}$ found similar results when they assessed maternal intakes of folate, vitamin $\mathrm{B}_{12}$, choline, betaine and methionine during the first and second trimesters of pregnancy. For betaine and choline a lower mean intake was found during the second trimester of pregnancy, an increase in mean intake was found for methionine, and no changes were found in mean intake for folate. Seasonal variation cannot explain this difference because both FFQ were administered during spring. A possible explanation is that boredom was higher and motivation was lower during the second administration.

In the present study, the intra-class correlation coefficients between the first and the second FFQ ranged from 0.62 for betaine to 0.83 for folate. These good correlations between the repeated administrations indicate that the random response error, sometimes due to lack of interest or motivation of the respondent, is rather small. In reproducibility studies, the correlation coefficients generally range from 0.5 to $0 \cdot 7$. Bidulescu et al. ${ }^{(34)}$ reported correlations of 0.49 (folate) and 0.48 (choline) in men and women aged 45-64 years using a version of the Willett sixty-one-item FFQ. A study on intake of methyl-group donors during the first and second trimesters of pregnancy using a 166-item FFQ showed correlations of 0.32, 0.55, 0.51 and 0.43 for folate, choline, betaine and methionine, respectively ${ }^{(33)}$. These correlations are lower than the correlations reported in the present study: 0.83 (folate), 0.80 (choline), 0.62 (betaine) and 0.78 (methionine). This lower correlation for folate $(0.55)$ was also found by Longnecker et $a l .{ }^{(26)}$. On the other hand, a high correlation for folate $(0 \cdot 72)$ was also found by Pufulete et al. ${ }^{(28)}$ who similarly assessed the intake of folate (in women) with a short newly developed FFQ.

The cross-classification analysis and $\kappa_{\mathrm{W}}$ values indicated a moderate to good agreement between the repeated administrations, with a maximal misclassification of $7 \%$ for betaine.

\section{Strengths and limitations}

To our knowledge, the present study is the first validation study that assesses the intake of methyl-group donors with a newly developed FFQ designed for these specific nutrients. This FFQ will be used in an observational study, providing us with a convenient and reliable instrument to rank individuals according to their intake of methyl-group donors $^{(11)}$. A key step in the validation process is the selection of a reference method for the tool to be validated against. Since there is no gold standard, it is important that the errors of both methods are as independent as possible. The EDR was chosen as reference method in the present study. Unlike the FFQ method, the EDR does not depend on memory, is moreover open-ended and involves direct estimation of portion size $\mathrm{i}^{(11)}$. The EDR also takes into account the within-person variability in food intake, which is necessary because in women there is a strong dayof-the-week effect ${ }^{(20)}$. Therefore intra-class correlations were 
corrected for attenuation, which improved the correlations for all nutrients. EDR (instead of weighed diet records) were used because they have the same order of accuracy when ranking individuals and the respondent burden is lower ${ }^{(35)}$. Food diaries with seven consecutive recording days were used to deal with day-to-day variation and to cover all days of the week equally. Seven consecutive dietary records might decrease the subject compliance and therefore decrease the accuracy of the dietary records collected at the end of the $7 \mathrm{~d}$ period. Therefore, we compared the energy intake calculated during the first three record days with that calculated during the last three record days. There was no significant difference $(P=0 \cdot 121)$ between energy intakes from the first $3 \mathrm{~d}$ and last $3 \mathrm{~d}$. Structured diaries, as well as an example for filling in the EDR, guided the women to report all consumption, even for easily forgotten snacks such as soft drinks and candy. In the literature we found a wide range in sample sizes to assess validity and reproducibility, with a median of 110 participants. A sample size of at least fifty, and preferably 100 or more participants, is desirable ${ }^{(11)}$. Because the performance of a dietary assessment instrument depends on the characteristics of the study population and considering the target population in which the FFQ will be used, women of reproductive age (18-35 years) were recruited, leaving us with a large sample size and homogeneous group of women.

A limitation of this method is that it requires high motivation of the participants (many recording days), lack of which may lead to under-reporting of intake and inadequate food description ${ }^{(13)}$. In the present study, $61 \%$ of the participants returned two FFQ and an EDR. This is a good response rate knowing how intensive it is to fill in the $7 \mathrm{~d}$ EDR. It was higher than the $15 \%$ response rate seen in other validation studies ${ }^{(36)}$. Women who filled in an EDR were promised nutritional advice in return, leading to some selection bias of volunteers who are more concerned about health and diet. But forcing non-motivated women to participate in the study might influence the quality of the data as well ${ }^{(37)}$. A limitation for the reproducibility study could be a possible memory effect during completion of the second FFQ as women could possibly remember what they filled in 6 weeks ago. Furthermore, because of dietary changes, for example food cravings and aversions, nausea, vomiting ${ }^{(38,39)}$, during pregnancy and even possible dietary restrictions (e.g. restrictions to avoid toxoplasmosis), it might be more difficult to complete such FFQ during pregnancy. However, because of logistical reasons it was not feasible to perform this validation study in a group of pregnant women.

One methyl-group donor, folic acid, derived from the diet is missing from our FFQ. In Belgium many food items, for example breakfast cereals, are enriched with folic acid. At this time point there is no list available of food items enriched with folic acid in Belgium, and folic acid is not included in the Belgian food composition database.
Food folate (without folic acid) was used to calculate the daily folate intake, since the fortification of products is different in other countries. Therefore the intake of folic acid could not be calculated. A last limitation is the use of food composition databases from different countries. Differences between databases include description of foods, calculation of nutrient content, recipe calculation, etc. ${ }^{(40)}$.

\section{Conclusion}

The results found in the present validation and reproducibility study indicate that the FFQ is a reliable instrument with acceptable validity for ranking according to methylgroup donor intakes (except for a poor agreement for choline $\left(\kappa_{\mathrm{w}}=0 \cdot 10\right)$ and a fair ranking ability for betaine $(r=0 \cdot 32))$ in Flemish women of reproductive age.

\section{Acknowledgments}

Acknowledgements: The authors acknowledge the women who volunteered to take part in the study. Financial support: Funding for the present study was provided by a PhD grant (grant number 11B1812N) from The Research Foundation-Flanders (FWO) and the Flemish Institute of Technological Research (VITO). FWO and VITO had no role in the design, analysis or writing of this article. Conflict of interest: None. Authorship: S.P. and I.D. were responsible for the field work and data entry. I.H. helped with the statistical analysis of the results. All authors helped in the evaluation of the results and the writing of the manuscript. All authors have read and have approved the manuscripts before submission. Ethics of buman subject participation: The study was approved by the UZ Leuven-Committee for Medical Ethics (reference number: ML7975).

\section{Supplementary material}

To view supplementary material for this article, please visit http://dx.doi.org/10.1017/S1368980014003140

\section{References}

1. Parle-McDermott A \& Ozaki M (2011) The impact of nutrition on differential methylated regions of the genome. $A d v$ Nutr 2, 463-471.

2. McKay JA \& Mathers JC (2011) Diet induced epigenetic changes and their implications for health. Acta Physiol (Oxf) 202, 103-118.

3. Chmurzynska A (2010) Fetal programming: link between early nutrition, DNA methylation, and complex diseases. Nutr Rev 68, 87-98.

4. Dominguez-Salas P, Cox SE, Prentice AM et al. (2012) Maternal nutritional status, C(1) metabolism and offspring DNA methylation: a review of current evidence in human subjects. Proc Nutr Soc 71, 154-165. 
5. King WD, Ho V, Dodds L et al. (2012) Relationships among biomarkers of one-carbon metabolism. Mol Biol Rep 39, 7805-7812.

6. US Department of Agriculture, Agricultural Research Service (2008) USDA Database for the Choline Content of Common Foods. http://www.ars.usda.gov/SP2UserFiles/Place/80400525/ Data/Choline/Choln02.pdf (accessed October 2012).

7. Mason JB (2003) Biomarkers of nutrient exposure and status in one-carbon (methyl) metabolism. J Nutr 133, Suppl. 3, 941S-947S.

8. Heijmans BT, Tobi EW, Stein AD et al. (2008) Persistent epigenetic differences associated with prenatal exposure to famine in humans. Proc Natl Acad Sci U S A 105, 17046-17049.

9. Tobi EW, Slagboom PE, van Dongen J et al. (2012) Prenatal famine and genetic variation are independently and additively associated with DNA methylation at regulatory loci within IGF2/H19. PLoS One 7, e37933.

10. Steegers-Theunissen RP, Obermann-Borst SA, Kremer D et al. (2009) Periconceptional maternal folic acid use of 400 microg per day is related to increased methylation of the IGF2 gene in the very young child. PLoS One $\mathbf{4}$, e7845.

11. Cade J, Thompson R, Burley V et al. (2002) Development, validation and utilisation of food-frequency questionnaires a review. Public Health Nutr 5, 567-587.

12. Bolca S, Huybrechts I, Verschraegen M et al. (2009) Validity and reproducibility of a self-administered semi-quantitative food-frequency questionnaire for estimating usual daily fat, fibre, alcohol, caffeine and theobromine intakes among Belgian post-menopausal women. Int J Environ Res Public Health 6, 121-150.

13. Willett W (2012) Nutritional Epidemiology, 3rd ed. New York: Oxford University Press.

14. NEVO Foundation (2011) NEVO (Nederlands voedingsstoffenbestand) Dutch Food Composition Table. Zeist: NEVO Foundation.

15. Dehne LI, Klemm C, Henseler G et al. (1999) The German Food Code and Nutrient Data Base (BLS II.2). Eur J Epidemiol 15, 355-359.

16. Ministry of Public Health (2010) NUBEL (Nutriënten België) Belgian Food Composition Table. Brussels: Ministry of Public Health.

17. V.z.w. NUBEL (2010) Nubel (Nutriënten België) VoedingsPlanner. Brussels: v.z.w. NUBEL.

18. Superior Health Council (2005) Maten en gewichten (Measures and weights). Handleiding voor gestandaardiseerde kwantificering van voedingsmiddelen in België: revision januari 2005. Brussels: Superior Health Council.

19. Portney LG \& Watkins MP (2000) Foundations of Clinical Research: Applications to Practice, 2nd ed. Upper Saddle River, NJ: Prentice Hall.

20. Beaton GH, Milner J, Corey P et al. (1979) Sources of variance in 24-hour dietary recall data: implications for nutrition study design and interpretation. Am J Clin Nutr 32, 2546-2559.

21. Bland JM \& Altman DG (1986) Statistical methods for assessing agreement between two methods of clinical measurement. Lancet 1, 307-310.

22. Altman DG (1991) Practical Statistics for Medical Research. London: Chapman \& Hall.

23. Hoge Gezondheidsraad (2011) Advies van de Hoge Gezondheidsraad nr. 8623. Foliumzuur, risk-benefit analyse. http://www.health.belgium.be/internet2Prd/groups/ public/@public/@shc/documents/ie2divers/19074148.pdf (accessed August 2012).
24. World Health Organization, Food and Agriculture Organization of the United Nations \& United Nations University (2007) Protein and Amino Acid Requirements in Human Nutrition. Report of a Joint FAO/WHO/UNU Expert Consultation. WHO Technical Report Series no. 935. Geneva: WHO.

25. Institute of Medicine, Standing Committee on the Scientific Evaluation of Dietary Reference Intakes and its Panel on Folate Other B Vitamins, and Choline (1998) Dietary Reference Intakes for Thiamin, Riboflavin, Niacin, Vitamin $B_{6}$, Folate, Vitamin $B_{12}$, Pantothenic Acid, Biotin, and Choline. Washington, DC: National Academies Press.

26. Longnecker MP, Lissner L, Holden JM et al. (1993) The reproducibility and validity of a self-administered semiquantitative food frequency questionnaire in subjects from South Dakota and Wyoming. Epidemiology 4, 356-365.

27. Sevak L, Mangtani P, McCormack V et al. (2004) Validation of a food frequency questionnaire to assess macro- and micro-nutrient intake among South Asians in the United Kingdom. Eur J Nutr 43, 160-168.

28. Pufulete M, Emery PW, Nelson M et al. (2002) Validation of a short food frequency questionnaire to assess folate intake. Br J Nutr 87, 383-390.

29. Feskanich D, Rimm EB, Giovannucci EL et al. (1993) Reproducibility and validity of food intake measurements from a semiquantitative food frequency questionnaire. $J \mathrm{Am}$ Diet Assoc 93, 790-796.

30. Salvini S, Hunter DJ, Sampson L et al. (1989) Food-based validation of a dietary questionnaire: the effects of week-to-week variation in food consumption. Int J Epidemiol 18, 858-867.

31. Krebs-Smith S, Heimendinger J, Subar A et al. (1995) Using food frequency questionnaires to estimate fruit and vegetable intake: association between number of questions asked and total intakes. J Nutr Educ 27, 80-85.

32. Zeisel SH, Mar MH, Howe JC et al. (2003) Concentrations of choline-containing compounds and betaine in common foods. J Nutr 133, 1302-1307.

33. Villamor E, Rifas-Shiman SL, Gillman MW et al. (2012) Maternal intake of methyl-donor nutrients and child cognition at 3 years of age. Paediatr Perinat Epidemiol 26, 328-335.

34. Bidulescu A, Chambless LE, Siega-Riz AM et al. (2009) Repeatability and measurement error in the assessment of choline and betaine dietary intake: the Atherosclerosis Risk in Communities (ARIC) study. Nutr J 8, 14.

35. Chinnock A (2006) Validation of an estimated food record. Public Health Nutr 9, 934-941.

36. Bingham SA, Gill C, Welch A et al. (1994) Comparison of dietary assessment methods in nutritional epidemiology: weighed records $v .24 \mathrm{~h}$ recalls, food-frequency questionnaires and estimated-diet records. BrJ Nutr 72, 619-643.

37. De Henauw S, Brants HA, Becker W et al. (2002) Operationalization of food consumption surveys in Europe: recommendations from the European Food Consumption Survey Methods (EFCOSUM) Project. Eur J Clin Nutr 56, Suppl. 2, S75-S88.

38. Bayley TM, Dye L, Jones S et al. (2002) Food cravings and aversions during pregnancy: relationships with nausea and vomiting. Appetite 38, 45-51.

39. Niebyl JR (2010) Clinical practice. Nausea and vomiting in pregnancy. $N$ Engl J Med 363, 1544-1550.

40. Hakala P, Knuts LR, Vuorinen A et al. (2003) Comparison of nutrient intake data calculated on the basis of two different databases. Results and experiences from a SwedishFinnish study. Eur J Clin Nutr 57, 1035-1044. 